\title{
Mitigative effects of Moringa oleifera against liver injury induced by artesunate- amodiaquine antimalarial combination in wistar rats
}

Mitchel Otieno Okumu ${ }^{1 *}$, Francis Okumu Ochola², James Mucunu Mbaria', Laetitia Wakonyu Kanja', Daniel Waweru Gakuya ${ }^{3}$, Alice Wairimu Kinyua ${ }^{3}$, Paul Onyango Okumu ${ }^{4}$ and Stephen Gitahi Kiama ${ }^{5}$

\begin{abstract}
Background: Artesunate-amodiaquine (AS-AQ) is an antimalarial drug. It is associated with improved cure rates, accelerated response to therapy and delayed development of resistance. However, liver damage, neurotoxicity and agranulocytosis have been reported as adverse effects whose origins have been linked to free radicals generated by the drug. According to native materia medica, Moringa oleifera (MO) has wide utility in ethnomedicine. However, there is paucity of information on the hepatoprotective efficacy of this plant. The present study evaluated the mitigative effects of $\mathrm{MO}$ leaf extracts against liver injury induced by AS-AQ combination in female Wistar rats.

Methods: Dry leaf powder of $M O$ was extracted with water and a 20:80 v/V mixture of water and methanol to give aqueous (AQ) and aqueous-methanol (AQ-ME) MO leaf extracts respectively. In vitro hydroxyl free radical scavenging activity of serial dilutions $(10-100 \mu \mathrm{g} / \mathrm{ml})$ of each of the extracts was then evaluated using an assay model where butylated hydroxytoluene (BHT) served as a reference standard. The extract with better free radical scavenging activity was then evaluated for hepatoprotective effects against AS-AQ intoxication in female Wistar rats based on the Acute Toxic Class method (OECD 2000). Serum asparate amino transferase (AST), alanine amino transferase (ALT), total bilirubin and histological examination of rat liver sections were used to evaluate the hepatoprotective activity of the selected MO leaf extract. Siliphos (standard hepatoprotectant) was used for comparison.

Results: There was a concentration dependent increase in the hydroxyl free radical scavenging activity of $\mathrm{MO}$ leaf extracts and standard (BHT) with values ranging from 46.36-66.36\% for the AQ extract, 41.04-60.95\% for the AQ-ME extract and $44.93-65.23 \%$ for BHT with corresponding $I_{50}$ values of $26.84 \mu \mathrm{g} / \mathrm{ml}, 51.88 \mu \mathrm{g} / \mathrm{ml}$ and $32.58 \mu \mathrm{g} / \mathrm{ml}$ respectively. A $1000 \mathrm{mg} / \mathrm{kg}$ dose of the AQ-ME MO leaf extract significantly $(p<0.05)$ lowered AST values of AS-AQ intoxicated rats to a level comparable to the standard hepatoprotectant; Siliphos. Serum ALT and TB were also lowered but this was not statistically significant $(p>0.05$ ). The $1000 \mathrm{mg} / \mathrm{kg}$ dose also reduced hepatocyte degeneration in rats treated with four times the clinical dose of AS-AQ. This study suggests that the hepatoprotective activity of the leaves of $M O$ may have some relation to its free radical scavenging properties. These leaves may thus be useful in mitigating free radical initiated disease conditions.

Conclusion: The aqueous-methanol Moringa oleifera leaf extract exhibits free radical scavenging and hepatoprotective properties. Further investigations on the structural identity of the phytoconstituents and their mechanisms of action should be performed to facilitate the development of a potent medicinal agent.
\end{abstract}

Keywords: Moringa oleifera, Artesunate-amodiaquine, Hepatoprotective activity, Wistar rats

\footnotetext{
* Correspondence: mytchan88@gmail.com

'Department of Public Health, Pharmacology and Toxicology, Faculty of

Veterinary Medicine, University of Nairobi, P.O BOX 29053-00625, Nairobi, Kenya

Full list of author information is available at the end of the article
} 


\section{Background}

Intimate proximity of the liver to the small intestines and blood circulation exposes it to many foreign substances or their metabolites which may induce injury [1]. Access to antimalarials in the African region is unabated resulting in unwarranted self-medication practices whose net result may be untoward effects such as toxicity [2,3]. Artesunate-amodiaquine is a fixed dose combination currently in use for the treatment of uncomplicated malaria [4]. At high doses, the drug causes liver damage, neurotoxicity and agranulocytosis associated to free radicals generated by the drug $[5,6]$. Siliphos is an antioxidant substance made up of a complex of silybin (a flavonoid) and phosphatidylcholine (a phospholipid). This complex has been reported to have good hepatoprotective activity [7]. MO is a plant associated with antioxidant properties [8]. Positive correlations have been made between the antioxidant and hepatoprotective properties of other plants such as Acacia catechu, Camellia sinensis, Magnifera indica, Punica granatum and Phyllanthus emblica [9]. However, there is paucity of information on the antioxidant and hepatoprotective effects of MO. The present study aims to determine the antioxidant and protective effects of leaves of $M O$ on the liver of artesunate-amodiaquine intoxicated female Wistar rats.

\section{Methods}

\section{Chemicals}

Pure artesunate drug powder (SIGMA A3731), pure amodiaquine drug powder (FLUKA A2799) and phosphate buffer saline (PBS) tablets were purchased from SigmaAldrich chemical company (St. Louis, MO). Siliphos was purchased from iherb, California USA and diagnostic kits (MIND-RAY) were purchased from SHENZEN MINDRAY Biomedical electronics, Shenzen, China. All other reagents were analytical grade and of high purity.

\section{Collection and identification of plant material}

Fresh aerial plant material of $M O$ was collected from Kibwezi, Makueni county in Kenya $\left(2^{\circ} 25 S^{\prime} 37^{\circ} 58^{\prime} \mathrm{E}\right)$ (Fig. 1). The leaves were carefully seperated from the plant, duplicate samples prepared and authenticated by a botanist at the National Museums Herbarium. A voucher specimen number (NMK/BOT/CTX/1/2) was assigned to the specimen for future reference.

\section{Preparation of extracts}

Leaves of $M O$ were air-dried under shade for 1 week and powdered using an electric mill. A slightly modified method of Anwar et al., [10] was used to prepare water and aqueous-methanol extracts. For the aqueous extract, one hundred grams of dry $M O$ leaf powder was weighed and poured into a $500 \mathrm{ml}$ volumetric flask wrapped in tin foil. Water was gradually added to this flask and the flask gently shaken until a slurry of uniform consistency was formed. The contents were then stirred by use of a magnetic stirrer for $48 \mathrm{~h}$ and subsequently centrifuged at 3000 RPM for $10 \mathrm{~min}$. The supernatant was collected into amber coloured plastic bottles and freeze dried to obtain a dry lyophilized powder which was weighed and kept in air-tight containers awaiting further work.

Similarly, the aqueous-methanolic extract was prepared by weighing one hundred grams of dry $M O$ leaf powder into a $500 \mathrm{ml}$ volumetric flask wrapped in tin foil. A mixture of water and methanol $(20: 80 \mathrm{v} / \mathrm{v})$ was gradually added to this flask and the flask gently shaken until a slurry of uniform consistency was formed. The contents were then stirred using a magnetic stirrer for $48 \mathrm{~h}$ and subsequently centrifuged at 3000 RPM for $10 \mathrm{~min}$, supernatant collected and poured into a round bottomed flask. Owing to the different boiling points of water and methanol, the round bottomed flask was then attached to a rotary evaporator whose operating temperature was then set at $40{ }^{\circ} \mathrm{C}$. The setup was allowed to run for $6 \mathrm{~h}$ to remove methanol after which the semisolid mass was transferred to a $40{ }^{\circ} \mathrm{C}$ sand bath and left overnight. The resulting solid mass was then collected and stored in air-tight containers awaiting further work.

\section{Determination of hydroxyl radical scavenging activity}

The method of Klein et al., [11] was used. Briefly, extract concentrations $(10-100 \mu \mathrm{g} / \mathrm{ml})$ were added to a $3 \mathrm{ml}$ mixture containing $1.5 \mathrm{mM}$ Ferrous sulphate, $6 \mathrm{mM}$
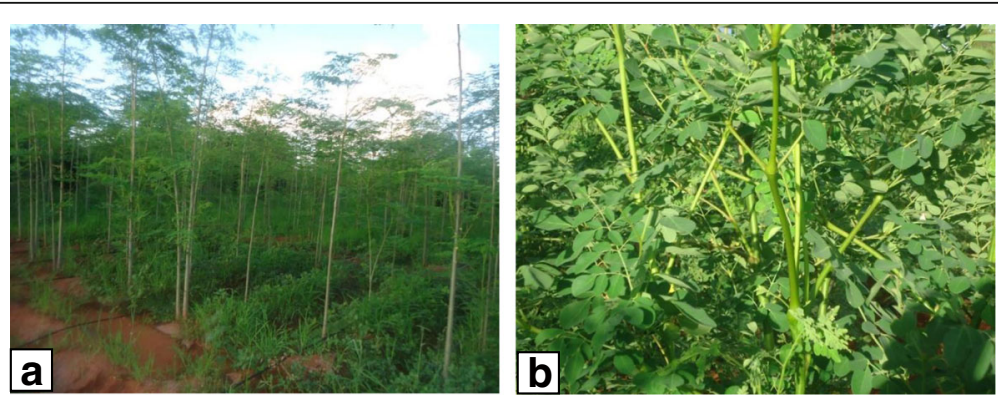

Fig. 1 a Moringa oleifera whole plant $\mathbf{b}$ aerial parts of Moringa oleifera 
hydrogen peroxide and $20 \mathrm{mM}$ sodium salicylate. The resulting solution was then incubated at $37{ }^{\circ} \mathrm{C}$ for $1 \mathrm{~h}$. The intensity of the colour developed was measured at $532 \mathrm{~nm}$ using a Spectronic 21D Milton Roy UV-VIS Spectrophotometer (USA). The capacity of the samples to scavenge hydroxyl free radicals was calculated using the formula as described by Singh et al., [12].

\%Scavenging capacity of sample extracts on hydroxyl radicals $=\frac{\mathrm{A}_{\text {Control }}-\mathrm{A}_{\text {Sample }}}{\mathrm{A}_{\text {Control }}} \times 100$

Where;

$\mathrm{A}_{\text {Control }}=$ Absorbance of the control (Ferrous sulphate, hydrogen peroxide and sodium salicylate).

$\mathrm{A}_{\text {Sample }}=$ Absorbance of the sample (Ferrous sulphate, hydrogen peroxide, sodium salicylate and varied concentrations of leaf extracts of $M O$.

The concentration of the extracts which inhibited 50\% of hydroxyl radicals was calculated using regression analysis in MS Excel 2007.

\section{Ethical considerations}

Before commencing in vivo studies in Wistar rats, ethical clearance was sought from the biosafety, animal use and ethics committee of the University of Nairobi. A reference number was given for future reference BAUEC/J56/76385/2014.

\section{Occupational health and personal protective equipment (PPE)}

Established protocols [13] for handling laboratory animals were followed throughout the study. Latex hand gloves and protective masks were used at all times. In addition, anti-tetanus and anti-rabies vaccines were made available and stored under refrigeration.

\section{Preparation of animals}

Thirty-six healthy, 8-10 week old female Wistar rats weighing 180-200 g were used for the study. The animals were nulliparious and non-pregnant and were purchased from the animal holding unit of the Department of Public Health, Pharmacology and Toxicology of the University of Nairobi. They were then housed in polypropylene cages measuring $35(\mathrm{~L}) \times 25(\mathrm{~W}) \times 18(\mathrm{H})$ and lined with wood shavings. Temperature of the animal house was maintained at $25 \pm 3{ }^{\circ} \mathrm{C}$ and $50-60 \%$ relative humidity for a period of 10 days to enable the animals to acclimate to the laboratory conditions. A 12-h light and dark cycle was maintained and the animals were sustained on water ad libitum and standard rat pellets from a commercial feed supplier (Unga feeds, Kenya Limited).

\section{Experimental design}

From our previous studies on acute oral toxicity of $M O$ [14], a $1000 \mathrm{mg} / \mathrm{kg}$ dose of the aqueous-methanol $M O$ leaf extract was used in evaluating hepatoprotective activity against AS-AQ intoxication. Thirty six rats were randomly assigned to 12 groups (each 3 animals) based on the Acute Toxic Class method [15]. The animals were labelled to enable identification. All test substances; Siliphos, $M O$, AS-AQ were dissolved in physiological buffer saline (PBS) for administration to rats by oral gavage over a 5-day period as follows;

Group I- Orally received $2 \mathrm{ml}$ of PBS once daily. Group II- Orally received a $1000 \mathrm{mg} / \mathrm{kg}$ dose of $M O$ leaf extract once daily.

Group III- Orally received $200 \mathrm{mg} / \mathrm{kg}$ of Siliphos once daily. Group IV-Orally received 4, 2, 2, 2,2 $\mathrm{mg} / \mathrm{kg}$ of artesunate (AS) and 10.8, 5.4, 5.4, 5.4 and $5.4 \mathrm{mg} / \mathrm{kg}$ dose of amodiaquine (AQ). This is equivalent to the clinical dose of AS-AQ for the treatment of uncomplicated malaria $[16,17]$ and is referred to in this experiment as clinical dose of AS-AQ.

Group V-Orally received 8,4,4,4 and $4 \mathrm{mg} / \mathrm{kg}$ dose of artesunate (AS) and 21.6, 10.8, 10.8, 10.8 and $10.8 \mathrm{mg} / \mathrm{kg}$ dose of amodiaquine (AQ). This is equivalent to double the clinical dose of AS-AQ $(2 \times$ clinical dose of AS-AQ). Group VI- Orally received 16, 8, 8, 8 and $8 \mathrm{mg} / \mathrm{kg}$ of artesunate (AS) and 43.2, 21.6, 21.6, 21.6 and $21.6 \mathrm{mg} / \mathrm{kg}$ of amodiaquine (AQ). This is equivalent to four times the clinical dose of AS-AQ ( $4 \times$ clinical dose of AS-AQ). Group VII-Rats were first orally pre-treated with a $200 \mathrm{mg} / \mathrm{kg}$ dose of the standard hepatoprotectant (Siliphos ) followed an hour later by treatment with the clinical dose of AS-AQ as previously described. Group VIII- Rats were orally pre-treated with a $200 \mathrm{mg} / \mathrm{kg}$ dose of the standard hepatoprotectant (Siliphos) followed an hour later by treatment with $2 \times$ clinical dose of AS-AQ as previously described. Group IX- Rats were first orally pre-treated with a $200 \mathrm{mg} / \mathrm{kg}$ dose of the standard hepatoprotectant (Siliphos') followed an hour later by treatment with $4 \times$ clinical dose of AS-AQ as previously described. Group X- Rats were first orally pre-treated with a $1000 \mathrm{mg} / \mathrm{kg}$ dose of $M O$ leaf extract followed an hour later by treatment with the clinical dose of AS-AQ as previously described.

Group XI- Rats were first orally pre-treated with a $1000 \mathrm{mg} / \mathrm{kg}$ dose of $\mathrm{MO}$ leaf extract followed an hour later by treatment with $2 \times$ clinical dose of AS-AQ as previously described.

Group XII- Rats were first orally pre-treated with a $1000 \mathrm{mg} / \mathrm{kg}$ dose of $M O$ leaf extract followed an hour later by treatment with $4 \times$ clinical dose of AS-AQ as previously described. 
Blood collection, necropsy and disposal of rat carcasses Twenty-four hours after administration of the last treatment, individual animals were held with a warm cloth to dilate the blood vessels. The lateral tail vein was then gently punctured using a 21-gauge hypodermic needle attached to a $2 \mathrm{ml}$ syringe. One $\mathrm{ml}$ of blood was allowed to collect in the syringe and then transferred to vacutainers lined with a clot activator. The clotted blood was then centrifuged at 3000 RPM for $10 \mathrm{~min}$ and serum collected by use of micropipettes into cryo-vials which were capped and stored at $4{ }^{\circ} \mathrm{C}$ awaiting biochemical analysis. The levels of serum aspartate aminotransferase (AST), alanine amino transferase (ALT) and total bilirubin (TB) in the different treatment groups were assayed using standard protocols of MIND-RAY commercial kits [18]. Animals were then humanely euthanized by use of a $150 \mathrm{mg} / \mathrm{kg}$ dose of intravenous sodium pentobarbital injection. Livers were harvested, weighed and preserved in $10 \%$ neutral buffered formalin solution for $24 \mathrm{~h}$ awaiting histological examination. Rodent carcasses were then placed in zip locked non-polyvinylchloride (non-PVC) transparent plastic bags and incinerated.

\section{Histological examination}

A slightly modified method of Palipoch and Punsawad [19] was used. Formalin preserved liver tissues were washed with $70 \%$ ethanol. The tissues were then placed in metallic caskets, stirred by use of a stirrer followed by dehydration in graded ethanol (70-100\%) and embedded in paraffin wax by use of an embedding machine. The paraffinized blocks were then sectioned using a rotatory ultra microtome, transferred to glass slides and allowed to dry overnight. The slides were then stained by haemotoxylin and eosin (H\&E) dye and mounted on a light microscope for observation.

\section{Statistical analysis}

Results of the analysis of the hepatospecific markers of liver injury were expressed as mean \pm SEM and analyzed using one-way analysis of variance (ANOVA) followed by least significant difference as post hoc test using Gen Stat Statistical Software 4th edition. $(p \leq 0.05)$ was considered significant.

\section{Results}

\section{Hydroxyl radical scavenging capacity of Moringa oleifera leaf extracts}

It was shown on Fig. 2 that there was a concentration dependent increase in the in vitro hydroxyl radical scavenging activity of $M O$ extracts and butylated hydroxyl toluene (BHT). The scavenging activity of the AQ extract was in the range $46.36-66.36 \%$ compared to $41.04-60.95 \%$ of the AQ-ME extract and $44.93-65.23 \%$ of BHT. However, the ability of the AQ extract to

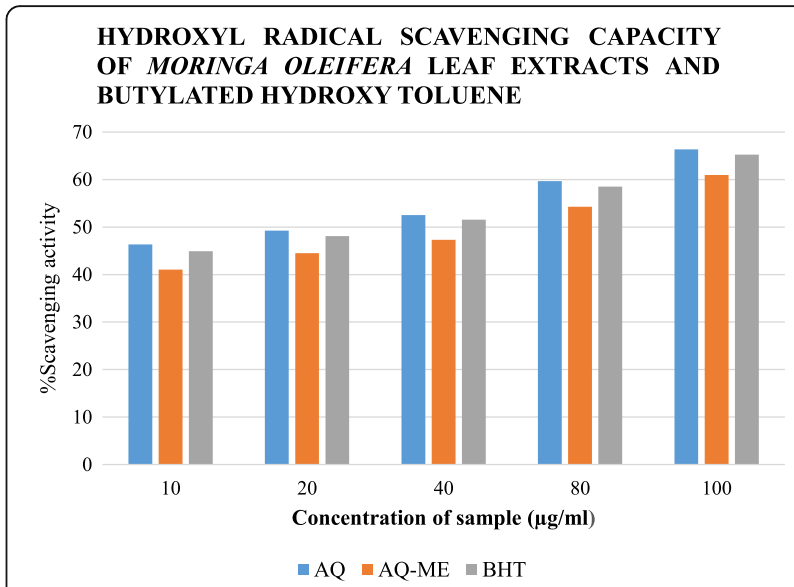

Fig. 2 Comparative analysis of hydroxyl radical scavenging capacity of $\mathrm{MO}$ leaf extracts relative to butylated hydroxy toluene (standard)

scavenge these free radicals $(66.36 \%)$ was found to be higher than both the AQ-ME extract (60.95\%) and BHT (65.23\%). Regression analysis in MS excel established the concentration of the extracts and standard necessary to inhibit $50 \%$ of the hydroxyl radicals $\left(\mathrm{IC}_{50}\right)$ Table 1.

\section{Changes in serum liver markers}

It was shown on Table 2, that there was a dose-dependent increase in the levels of AST, ALT and TB following treatment with the AS-AQ antimalarial combination. Moreover, pre-treatment with Siliphos $(200 \mathrm{mg} / \mathrm{kg}$ body weight per oral) and AQ-ME leaf extract of $M O$ at a dose of $1000 \mathrm{mg} / \mathrm{kg}$ body weight per oral significantly reduced the levels of serum AST but non-significantly reduced the levels of ALT and TB when compared to the AS-AQ intoxicated groups.

\section{Histological examination of rat liver sections}

It was shown on Fig. 3 that the administration of four times the clinical dose of AS-AQ resulted in vacuolation and necrosis of hepatocytes.

It was shown on Fig. 4 that pre-treatment of rats with a $1000 \mathrm{mg} / \mathrm{kg}$ dose of $M O$ before administration of four times the clinical dose of AS-AQ resulted in mild improvement in the degree of vacuolation and hepatic congestion.

Table $1 \mathrm{IC}_{50}$ values of $\mathrm{MO}$ leaf extracts and butylated hydroxy tolune (BHT) against hydroxyl free radicals

\begin{tabular}{ll}
\hline Sample & $\begin{array}{l}\mathrm{OH} \text { radical scavenging } \\
\text { activity }(\mu \mathrm{g} / \mathrm{ml})\end{array}$ \\
\hline Water (AQ) extract & 26.84 \\
Aqueous-methanol (AQ-ME) extract & 51.88 \\
Butylated hydroxyl toluene (BHT) & 32.58 \\
\hline
\end{tabular}


Table 2 Evaluation of the effect of MO leaf extract on AS-AQ intoxicated Wistar rats by using biomarkers of liver injury

\begin{tabular}{lllll}
\hline Group & Treatment code $(n=3)$ & AST $(\mathrm{IU} / \mathrm{L})$ & ALT (IU/L) & TB (mg/dl) \\
\hline 1 & PBS only & $122.37 \pm 13.73$ & $65.18 \pm 20.08$ & $0.83 \pm 0.67$ \\
2 & SCG & $127.67 \pm 25.07$ & $78.95 \pm 24.11$ & $3.08 \pm 1.30$ \\
3 & MCG & $113.93 \pm 5.46^{*}$ & $80.73 \pm 21.65$ & $1.69 \pm 0.38$ \\
4 & CD-ASAQ & $138.97 \pm 13.14$ & $76.44 \pm 0.85$ & $2.92 \pm 2.06$ \\
5 & $2 \times$ CD-ASAQ & $158.8 \pm 20.08$ & $85.70 \pm 17.55$ & $1.19 \pm 0.94$ \\
6 & $4 \times$ CD-ASAQ & $220.33 \pm 53.97^{*}$ & $90.39 \pm 13.62$ & $2.70 \pm 0.96$ \\
7 & S + CD-ASAQ & $130.97 \pm 16.61$ & $58.01 \pm 20.16$ & $1.15 \pm 0.57$ \\
8 & S + 2CD-ASAQ & $125.74 \pm 45.13$ & $64.47 \pm 23.65$ & $2.00 \pm 2.07$ \\
9 & S + 4CD-ASAQ & $184.00 \pm 23.60$ & $68.00 \pm 28.83$ & $2.93 \pm 2.32$ \\
10 & $M+$ CD-ASAQ & $138.77 \pm 24.33$ & $66.37 \pm 13.29$ & $0.53 \pm 0.35$ \\
11 & $M+2 C D-A S A Q$ & $171.13 \pm 52.88$ & $80.38 \pm 21.56$ & $1.61 \pm 0.80$ \\
12 & $M+4 C D-A S A Q$ & $140.03 \pm 24.45^{*}$ & $76.77 \pm 14.61$ & $1.17 \pm 0.66$ \\
\hline
\end{tabular}

Values are expressed as mean \pm SEM $(n=3)$ significantly different at ${ }^{*} p \leq 0.05$

$P B S$ physiological buffer saline, SCG siliphos control group, $M C G$ moringa control group, $C D$-ASAQ clinical dose of artesunate-amodiaquine, $2 \times C D$ - $A S-A Q$ double the clinical dose of artesunate-amodiaquine, $4 \times C D$-ASAQ four times the clinical dose of artesunate-amodiaquine, $S+C D$ - $A S A Q$ pre-treatment with Siliphos followed an hour later by treatment with a clinical dose of artesunate-amodiaquine, $S+2 * C D-A S A Q$ pre-treatment with Siliphos followed an hour later by treatment with double the clinical dose of ASAQ, $S+4 \times C D-A S A Q$ pre-treatment with Siliphos" followed an hour later by treatment with four times the clinical dose of ASAQ, $M+C D$ $A S A Q$ pre-treatment with the aqueous-methanol $M O$ leaf extract followed an hour later by treatment with the clinical dose of $A S-A Q, M+2 \times C D: A S A Q$ pre-treatment with the aqueous-methanol $M O$ leaf extract followed an hour later by treatment with double the clinical dose of $A S A Q, M+4 \times C D-A S A Q$ pre-treatment with the aqueous-methanol $M O$ leaf extract followed an hour later by treatment with four times the clinical dose of AS-AQ

\section{Discussion}

The hydroxyl free radical is one of the most potent reactive oxygen species in biological systems $[20,21]$. It undergoes chemical reactions with many components of biological cells such as amino acids, sugars, lipids and nucleotides which may result in cell damage $[20,21]$. Within biological systems, hydroxyl free radicals may be generated from the catalytic degradation of hydrogen peroxide [22]. In the in vitro context, the hydroxyl free radical may be generated by the Fenton reaction which involves the interaction of transition metals such as Iron II $\left(\mathrm{Fe}^{2+}\right)$ and hydrogen peroxide [23]. From the present study, we established a concentration dependent increase

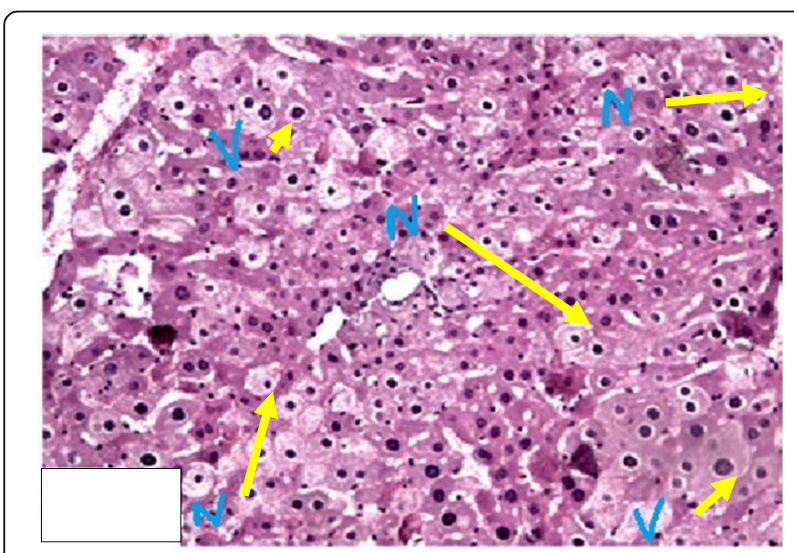

Fig. 3 Photomicrograph of liver section from a rat treated with four times the clinical dose of AS-AQ. (Magnification $\times 400$ ). $V=$ Hepatic vacuolation, $\mathrm{N}=$ Hepatic cell necrosis in the in vitro hydroxyl free radical scavenging effect of $M O$ leaf extracts. This observation is in agreement with the work of other authors [21, 22, 24]. Moreover, butylated hydroxy toluene (standard antioxidant) showed better scavenging capacity than both the aqueous and the aqueous-methanolic $M O$ leaf extracts. Based on the work of other workers [25-27], butylated hydroxytoluene is a synthetic compound made up of polyphenolics with marked antioxidant activity.

The inhibitory concentration value at $50 \%\left(\mathrm{IC}_{50}\right)$ refers to the concentration of the antioxidant substance sufficient to inhibit free radical activity by $50 \%$ [22]. The lower this value, the higher the antioxidant capacity of medicinal

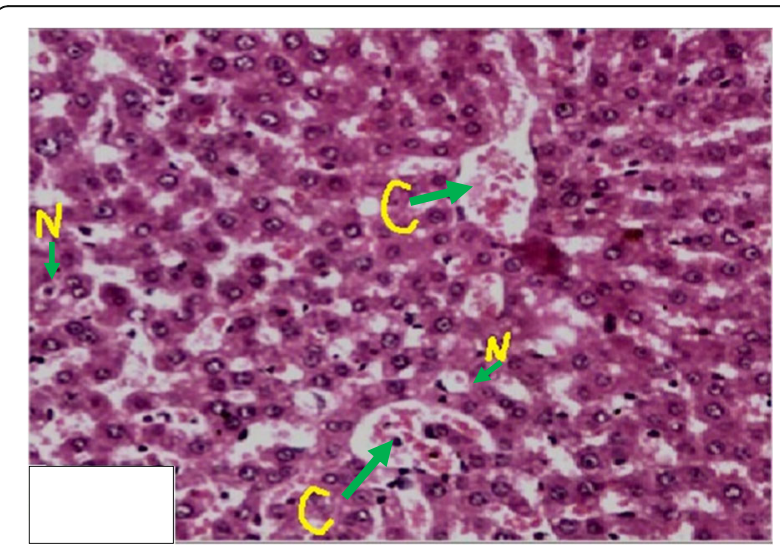

Fig. 4 Photomicrograph of liver section from a rat pre-treated with a $1000 \mathrm{mg} / \mathrm{kg}$ dose of aqueous-methanolic $\mathrm{MO}$ leaf extract and four times the clinical dose of ASAQ. (Magnification $\times 400)$. $C=$ Hepatic vein congestion, $N=$ Hepatic cell necrosis 
plants [22, 24]. The aqueous $M O$ leaf extract had a lower $\mathrm{IC}_{50}$ value than both the aqueous-methanolic $M O$ leaf extract and butylated hydroxytoluene. This may imply that the AQ $M O$ leaf may have better antioxidant properties than the AQ-ME $M O$ leaf extract. However, according to Moon and Shibamoto [28], at least two antioxidant assays should be used to evaluate the antioxidant properties of medicinal plants.

In our previous work [29], we reported the total phenolic, flavonoid and ascorbic acid contents of $M O$ leaf extracts. It is on the backdrop of these results that the aqueous-methanolic $M O$ leaf extract was selected for evaluation of hepatoprotective activity in Wistar rats.

There is a large body of literature available on the hepatoprotective activity of medicinal plants against carbon tetrachloride, ethanol or paracetamol toxicity [30-33]. However, the level of exposure of these chemicals to man may be very low. To the best of our knowledge, this is the first report of the protective effects of the aqueousmethanolic $M O$ leaf extract against AS-AQ induced liver injury in Wistar rats. This report is based on evidence of biochemical and histologic findings. Similar effects of liver protection were also observed in rats dosed with Siliphos, which was used as a positive control.

Siliphos is a complex of silybin and phosphatidylcholine [7]. The former is a flavonoid produced from the fruit of the milk thistle, Silybum marianum while the latter is a lipid-soluble derivative of soy. Given that silybin is lipidincompatible, the combination with phosphatidylcholine facilitates passage of the flavonoid through biological membranes [7]. Some workers have reported on the protective effect of Siliphos against carbon tetrachloride, acetaminophen, alcohol and mushroom poisoning [7, 34-36].

Artesunate-amodiaquine is an antimalarial agent. It comprises of artesunate and amodiaquine. The former is a potent and rapidly acting blood schizontocide while the latter is used in prophylaxis and treatment of malaria $[37,38]$. The drug is safe at therapeutic doses but high doses of artesunate causes congestion and dilation of hepatic sinudoids, vacuolation as well as necrosis [37]. A cytotoxic mechanism characterized by protein carbonylation, formation of reactive oxygen species and lipid peroxidation has been associated with the clinical use of amodiaquine [38].

In the present study, liver injury due to AS-AQ intoxication was observed as elevated levels of hepatospecific parameters like AST, ALT and TB. Studies on the histopathology of liver sections from rats treated with high doses of AS-AQ also corroborate findings of biochemical analysis. Hepatocytes carry out a host of metabolic activities under the influence of enzymes [39]. AST and ALT are found in higher concentrations in the cytoplasm. High levels of these enzymes in the serum may be indicative of loss of the functional integrity of hepatocytes and subsequent leakage of cell contents [40]. Group 6 rats $(4 \times$ AS-AQ dose) registered the highest elevation of these enzymes. However, since AST is also present in the kidney and cardiac muscles [40], it may be suggested that AS-AQ may have some toxic effects on these organs as well. Pre-treatment with $1000 \mathrm{mg} / \mathrm{kg}$ of the $M O$ leaf extract (group 12) significantly lowered the elevated levels of AST. This reduction was comparable to the control (group 3) and the hepatotoxic agent (group 6).

Bilirubin is a principle indicator of cholestatic liver injury [41]. In the present study, AS-AQ intoxicated rats were characterized by high serum bilirubin activity (group 4 and 6). However, the levels were not significantly different from the control group. This observation may suggest that AS-AQ may not be associated with cholestatic liver injury.

Histological examination of the liver sections of ASAQ intoxicated rats (group 6) showed significant hepatotoxicity characterized by vacuolation, necrosis of hepatocytes and congestion of central veins (Fig. 3). However, animals pre-treated with the aqueous alcoholic extract of $M O$ (group 12), the extent of hepatic distortion was decreased relative to the damage observed in the ASAQ intoxicated group (Fig. 4).

In our previous work on the aqueous methanolic extract of $M O$ leaf extract, we identified flavonoids, phenolics and ascorbic acid as phytoconstituents [29]. These secondary plant metabolites have been identified as natural antioxidants [23]. Thus, the observed free radical scavenging and hepatoprotective activities of the aqueous-methanolic $M O$ leaf extract may be attributable to the antioxidant phytoconstituents.

Discussions are still ongoing as to what effect is produced when AS-AQ and the MO leaf extract are concurrently used in a Plasmodium falciparum infected animal model. Some published works $[42,43]$ have reported on the effectiveness of $M O$ seeds on Plasmodium falciparum and Schistosoma cercariae. Nonetheless, similar activity is yet to be reported on the leaves. Other authors have suggested that antioxidants and supplements of herbal origin (grape fruit juice, orange fruit juice, ascorbic acid) may alter the efficacy of antimalarial drugs in clearing parasitaemia [44-46].

\section{Conclusion}

Based on our preliminary investigations it can be concluded that the aqueous-methanol Moringa oleifera leaf extract exhibits free radical scavenging and hepatoprotective properties. However, in a bid to develop a potent medicinal agent, further investigations on the structural identity of the phytoconstituents as well as the mechanism behind the observed effects should be performed. 


\section{Acknowledgments}

The authors would like to express their gratitude to Dr. Joshua Onono and Dr. Florence Mutua of the Department of Public Health, Pharmacology and Toxicology for providing assistance on statistical work. This work was financially supported by the Carnegie corporation of New York through Regional Initiative in Science and Education-African Natural Product Network (RISE-AFFNET).

\section{Authors' contributions}

MOO, AWK, POO participated in the conduction of experiments. FOO, JMM, LWK and DWG made substantial contributions to concept design and conduction of research. Data analysis and interpretation was done by MOO and POO. MOO, FOO, JMM and DWG participated in drafting the manuscript and LWK, SGK, POO, DWG revised the manuscript critically for intellectual content. MOO and AWK made the necessary corrections in the write up and JMM, DWG and SGK gave final approval for the submission of revised version. All authors read and approved the final manuscript.

\section{Competing interests}

The authors declare that they have no competing interest.

\section{Publisher's Note}

Springer Nature remains neutral with regard to jurisdictional claims in published maps and institutional affiliations.

\section{Author details 29053-00625, Nairobi, Kenya. \\ Received: 4 May 2017 Accepted: 14 July 2017 \\ Published online: 04 September 2017}

'Department of Public Health, Pharmacology and Toxicology, Faculty of Veterinary Medicine, University of Nairobi, P.O BOX 29053-00625, Nairobi, Kenya. ${ }^{2}$ Department of Pharmacology and Toxicology, Faculty of Medicine, Moi University, P.O BOX 3900-30100, Eldoret, Kenya. ${ }^{3}$ Department of Clinical Studies, Faculty of Veterinary Medicine, University of Nairobi, P.O BOX 29053-00625, Nairobi, Kenya. ${ }^{4}$ Department of Veterinary Pathology, Microbiology and Parasitology, Faculty of Veterinary Medicine, University of Nairobi, P.O BOX 29053-00625, Nairobi, Kenya. ${ }^{5}$ Department of Veterinary Anatomy and Physiology, Faculty of Veterinary Medicine, University of Nairobi, P.O BOX

\section{References}

1. Roy S, Bhattacharya S. Arsenic-induced histopathology and synthesis of stress proteins in liver and kidney of Channa Punctatus. Ecotoxicol Environ Saf. 2006;65(2):218-29.

2. Ruebush TK, Kern MK, Campbell CC, Oloo AJ. Self-treatment of malaria in rural areas of western Kenya. Bull World Health Organ. 1995;73(2):229-36.

3. Breman JG. The ears of the hippopotamus; manifestations, determinants and estimates of the malaria burden. Am J Trop Med Hyg. 2001;64(1-2):1-11.

4. Nosten F. White NJ Artemisinin-based combination treatment of falciparum malaria. Am J Trop Med Hyg. 2007;77(6):181-92.

5. Schramm B, Valeh P, Baudin E, Mazinda S, Smith R, Pinoges L, Sunday gar $T$, Zolla YM, Jones JJ, Conte E, Bruneel A, Branger M, Jullien V, Carn G, Kiechel JR, Ashley EA, Geurin PJ. Tolerability and safety of artesunate-amodiaquine and artemether-lumefantrine fixed dose combinations for the treatment of uncomplicated plasmodium falciparum malaria: two open-label, randomized trials in Nimba county, Liberia. Malar J. 2013;12:250

6. Davis TM, Binh TQ, llet KF, Batty KT, Phuong HL, Chiswell GM, Phuong VD, Agus C. Penetration of dihydroartemisinin into cerebrospinal fluid after administration of intravenous artesunate in severe falciparum malaria. Antimicrob Agents Chemother. 2003;47(1):368-70.

7. Kidd P, Head K. A review of the bioavailability and clinical efficacy of milk thistle phytosome: a silybin-phosphatidylcholine complex (Siliphos). Altern Med Rev. 2005;10(3):193-203.

8. Santos AF, Argolo AC, Paiva AC, Coelho LC. Antioxidant activity of Moringa Oleifera tissue extracts. Phytother Res. 2012;26(9):1366-70.

9. Hiraganahalli BD, Chinampudur VC, Dethe S, Mundkinajeddu D, Pandre MK, Balachandran J, Agarwal A. Hepatoprotective and antioxidant activity of standardized herbal extracts. Pharmacogn Mag. 2012;8(30):116-23.

10. Anwar F, Kalsoom U, Sultana B, Mushtaq M, Mehmood T, Arshad HA. Effect of drying method on the total phenolics and antioxidant activity of cauliflower (Brassica oleraceae. L) extracts. Int Food Res J. 2013;20(2):653-9.
11. Klein SM, Cohen G, Cederbaum Al. Production of formaldehyde during metabolism of dimethyl sulfoxide by hydroxyl radical generating system. Biochemist. 1981;20(21):6006-12.

12. Singh $\mathrm{R}$, Singh N, Saini BS, Rao HS. In vitro antioxidant activity of pet ether extract of black pepper. Indian J Pharmacol. 2008;40(4):147-51.

13. OECD. (2000). Guidance document on the recognition, assessment and use of clinical signs as humane endpoints for experimental animals used in safety evaluation. Series on testing and assessment.

14. Okumu MO, Mbaria JM, Kanja LW, Gakuya DW, Kiama SG, Ochola FO, Okumu PO. Acute toxicity of the aqueous-methanolic Moringa Oleifera (lam) leaf extract on female Wistar albino rats. Int J of Basic Clin Pharmacol. 2016;5(5):1856-61.

15. OECD. (2001).Test guideline 423: acute oral toxicity-acute toxic class method. OECD guidelines for the testing of chemicals.

16. Angus BJ, Thaiaporn I, Chanthapadith K, Suputtamongkol Y, White NJ. Oral artesunate dose-response relationship in acute falciparum malaria. Antimicrob Agents Chemother. 2002;46(3):778-82.

17. Obianime AW, Aprioku JS. Mechanism of action of artemisinins on biochemical, hematological and reproductive parameters in male guinea pigs. Int J Pharmacol. 2011;7(1):84-95.

18. Schumann G, Bonora R, Ceriotti F, Ferard G, Ferrero CA, PFH F, Gella FJ, Hoelzel W, Jorgensen PJ, Kanno T, Kessner A, Klauke A, Kristiansen N, Lessinger JM, TPJ L, Misaki H, Panteghini M, Pauwels J, Schiele F, Schimmel HG, Weidemann G, Siekmann L. IFCC primary reference procedures for the measurement of catalytic activity concentrations of enzymes at $37^{\circ} \mathrm{C}$. Part 5 . Reference procedure for the measurement of catalytic concentration of aspartate aminotransferase. Clin Chem Lab Med. 2002;40(7):725-33.

19. Palipoch S, Punsawad C. Biochemical and histological study of rat liver and kidney injury induced by Cisplatin. J Toxicol Pathol. 2013;26(3):293-9.

20. Alam MN, Bristi NJ, Rafiquzzaman M. Review on in vivo and in vitro methods evaluation of antioxidant activity. Saudi Pharm J. 2013;21(2):143-52.

21. Sowndhararajan K, Kang SC. Free radical scavenging activity from different extracts of leaves of Bauhinia Vahlii Wight \& Arn. Saudi J Biol Sci. 2013;20(4):319-25.

22. Adjimani JP, Asare P. Antioxidant and free radical scavenging activity of iron chelators. Toxicol Rep. 2015;2:721-8.

23. Duan $X, W u G$, Jiang $Y$. Evaluation of the antioxidant properties of litchi fruit phenolics in relation to pericarp browning prevention. Molecules. 2007;12(4):759-71.

24. Wang H, Gao XD, Zhou GC, Cai L, Yao WB. In vitro and in vivo antioxidant activity of aqueous extract from Choerospondias Axillaris fruit. Food Chem. 2008;106(3):888-95.

25. Habu JB, Ibeh BO. In vitro antioxidant capacity and free radical scavenging evaluation of active metabolite constituents of Newbouldia laevis ethanolic leaf extract. Biol Res. 2015;48(1):16.

26. Bjorkhem I, Henriksson-Freyschuss A, Breuer O, Diczfalusy U, Berglund L, Henriksson $P$. The antioxidant butylated hydroxytoluene protects against atherosclerosis. Arterioscler Thromb. 1991;11:15-22.

27. Sharma OP, Bhat TK. DPHH antioxidant assay revisited. Food Chem. 2009; 113(4):1202-5.

28. Moon JK, Shibamoto T. Antioxidant assays for plant and food components. J Agric Food Chem. 2009;57(5):1655-66.

29. Okumu MO, Mbaria JM, Kanja LW, Gakuya DW, Kiama SG, Ochola FO. Phytochemical profile and antioxidant capacity of leaves of Moringa oleifera (lam) extracted using different solvent systems. JPharmacognPhytochem. 2016;5(4):302-8

30. Nirmala M, Girija K, Lakshman K, Divya T. Hepatoprotective activity of Musa Paradisiaca on experimental animal models. Asian Pac J Tropic Biomed. 2012;2(1):5-11.

31. Kumar KE, Harsha KN, Sudheer V, Babu NG. In vitro antioxidant activity and in vivo hepatoprotective activity of the aqueous extract of Allium Cepa bulb in ethanol induced liver damage in rats. Food Sci Human Wellness. 2013; 2(3-4):132-8.

32. Krithika R, Verma RJ. Mitigation of carbon tetrachloride-induced damage by Phyllanthus Amarus in liver of mice. Acta Pol Pharm. 2009;66(4):439-44.

33. Senthilkumar R, Chandran R, Parimelazhagan T. Hepatoprotective effect of Rhodiola Imbricata rhizome against paracetamol-induced liver toxicity in rats. Saudi J Biol Sci. 2014;21(5):409-46.

34. Hikino H, Kiso Y, Wagner H, Fiebig M. Antihepatotoxic actions of flavonolignans from Silybum Marianum fruits. Planta Med. 1984;50:248-50.

35. Conti M, Malandrino S, Magistretti MJ. Protective activity of silipide on liver damage in rodents. Jpn J Pharmacol. 1992;60(4):315-21. 
36. Enjalbert F, Rapior S, Nouguier-Soule J, Guillon S, Amouroux N, Cabot C. Treatment of amatoxin poisoning:20-year retrospective analysis. J Toxicol Clin Toxicol. 2002;40(6):715-57.

37. Alyousif MS, Saifi MA, Ahmed M, Alouysif SM. Histopathological changes induced by artesunate in liver of Wistar rat. Int J Pharmacol. 2017;13(1):104-8.

38. Heidari $\mathrm{R}$, Babaei $\mathrm{H}$, Eghbal MA. Amodiaquine-induced toxicity in isolated rat hepatocytes and the cytoprotective effects of taurine and/or N-acetyl cysteine. ResPharmSci. 2014;9(2):97-105.

39. Aneja S, Vats M, Aggarwal S, Sardana S. Phytochemistry and hepatoprotective activity of the aqueous extract of Amaranthus Tricolor Linn. Roots. J.Ayurveda.Integr. Med. 2013:4(4):211-5.

40. Drotman RB, Lawhorn GT. Serum enzymes as indicators of chemically induced liver damage. Drug Chem Toxicol. 1978;1(2):163-71.

41. Achliya GS, Wadodkar SG, Dorle AK. Evaluation of hepatoprotective effect of Amalkadi ghrita against carbon tetrachloride induced hepatic damage in rats. JEthnopharmacol. 2004;90(2-3):229-32.

42. Gbeassor M, Kedjagni AY, Koumaglo K, De Souza C, Agho K, Aklikokou K, Amegho KA. In vitro antimalarial activity of six medicinal plants. Phytother Res. 1990;4(3):115-7.

43. Olsen A. Low technology water purification by bentonite clay and Moringa oleifera seed flocculation as performed in sudanese villages: effects on Schistosoma Mansoni cercariae. Water Res. 1987;21(5):517-22.

44. Talman AM, Dormarle O, McKenzie FE, Ariey F, Robert V. Gametocytogenesis: the puberty of plasmodium falciparum. Malar J. 2004:3:24.

45. Bledsoe GH. Malaria primer for clinicians in the United States. South Med J. 2005;98(12):1197-204.

46. Owira PM, Ojewole JA. The grapefruit: an old wine in a new glass? Metabolic and cardiovascular perspectives. Cardiovasc J Afric. 2010;21(5):280-5.

\section{Submit your manuscript to a SpringerOpen ${ }^{\bullet}$} journal and benefit from:

- Convenient online submission

- Rigorous peer review

- Open access: articles freely available online

- High visibility within the field

- Retaining the copyright to your article

Submit your next manuscript at $\gg$ springeropen.com 